\title{
English Film Appreciation from the Perspective of Cross Cultural Communication*
}

\author{
Tianyu Wang \\ University of Shanghai for Science and Technology, Shanghai, China \\ Gaofeng Yu \\ University of Shanghai for Science and Technology, Shanghai, China
}

\begin{abstract}
Under the background of globalization, as a way of cultural propagation, movies reflect the elements of cross-culture everywhere. This passage takes original English films, Zootopia and Forrest Gump as examples to stress that English learners should pay attention to some recessive cross-cultural elements, in addition to the explicit cultural elements such as plot, dialogue and oral English.
\end{abstract}

Index Terms - cross cultural context, dominant cultural elements, recessive cultural elements, English movie appreciation methods

\section{INTRODUCTION}

The occurrence of intercultural communication must be carried out among the nations or countries or individuals between two different cultural backgrounds, because there is a cultural difference, and there will be a "cultural barrier" in the middle of the communication. Yu Qiaoqin (2015) argues that the purpose of intercultural communication is to spread culture and eliminate cultural barriers. Liu Dan (2009) argues that since the 21 century, with the development of globalization, intercultural communication has become more frequent and has become a common social behavior nowadays. And As an artistic international language, film is one of the most important and most effective ways to promote international cultural exchange, transfer information and emotion, and the output of national culture. While the process of globalization is speeding up, the foreign language teaching in our country is constantly changing, and it has become a general trend to use foreign language video materials in the classroom. Especially for MTI students, our curriculum shouldn't just be simple listening, speaking, reading and writing, but also the training of intercultural communicative competence. Hymes believes that people with communicative competence need not only master the rules of language themselves, but also master the social rules of language usage so that they do not misread and speak when they communicate with different cultural backgrounds. Li Wenjing (2010) argues that English films have several main features, such as the authenticity of language materials, the diversity of language content and form, and the trinity of images and texts, views, listening and speaking. Therefore, the interest of the English film has become an important material for the cultivation of intercultural communication ability.

\section{The Characteristics AND AdVANT AgES OF THE ORIGINAL ENGLish FiLM}

\section{A. The Authenticity of Language and Scene}

How to create language environment is the key to learn foreign languages in Chinese environment. Any communicative behavior occurs on certain occasions, and the movie shows a real language environment and communicative scenario. By watching the original English movies, students can feel authentic English without leaving home. It is a problem for every English learner to apply the multimedia learning and the image of the film to the English learning, and to optimize the English ability by using the original film. The movie creates a real language environment. This language environment includes voice, culture and thinking. Monasteries in this environment will continue to improve the level of English. Li Wenjing (2010) argues that the original English movie originates from real life and takes the native language people as the object, makes scenes according to people's real life, so it has the authenticity characteristics. On the one hand, the material of the movie is true in language input. The film not only shows us the real words, intonation and phonetics, but also shows us various euphemisms, humorous words, metaphor, pun and so on, which are designed according to people's different identities and different characteristics. On the other hand, the movie based on image shows the real nonverbal behavior. In the film, in order to create a person's image, make the character more consistent with the situation, the actors try to deduce the real and natural nonverbal behavior, that is, the facial expression, gestures and the distance of the speech. Besides, the original English movie as a carrier reflects the western social culture, communication ways and values. By enjoying the original English movies, students

\footnotetext{
* This paper is supported by USST Humanities and Social Science Foundation 2017, (NO: SK2017ZD05)
} 
can get access to the real western culture, and more easily grasp the social rules of real language use. For example, in the film Forrest Gump, Gump said he could eat "one million and five hundred thousand chocolate", the word "million" means "a lot of " rather than the real meaning of itself. The analysis of this word shows a more intuitive understanding of the usages of exaggerated expressions in American daily expressions.

\section{B. Diversity of Content and Form}

English original films have a wide range of themes, involving people's way of life, thinking habits, traditional customs, religious beliefs and other aspects of the native English speaking countries and various subjects will present different life scenes for the audience, such as meetings, parties, visitors and so on. Through the appreciation of the original English films of different subjects, the students mobilize the corresponding cognitive areas in the brain and understand the differences between the western and Chinese cultures. In the subconscious, the western thinking and Chinese thinking will be compared to improve the ability of intercultural communication. In addition, there are various English original films, not only the teaching software of original English films, but also various online theaters on the Internet, which not only breaks the geographical restrictions of students' learning, but also provides convenience for students to study independently.

\section{The Interest of Many Aspects}

Movie is not only the carrier of language and culture, but also the embodiment of art. The original English version of the film, with the stereoscopic view, listening and speaking trinity, zigzag or suspense story plot and the feelings and ideas presented, can stimulate students' interest in learning more than any language education material. Krashen, a famous linguist, once pointed out that "the most important thing in language learning is listening comprehension, and listening training should be the first priority." However, in the domestic classroom, because of the lack of language environment, and the weak foundation of the students, they are ashamed to open the mouth and dare not to open their mouth. English original movies, which have various means of information transmission, have been gradually applied to English listening and speaking learning. At the same time, the original English film is the most intuitive and vivid comprehensive reflection of the social culture, life style, custom, culture, history and thinking mode of a nation and nation. It is an important carrier of broadcasting and Broadcasting Language and receiving knowledge by means of multimedia. It can fully mobilize people's sense of vision, hearing and feeling to receive language information. That's why we can see the original movie and improve the ability of English viewing, speaking and speaking. Because the improvement of English listening and speaking ability through the original film can make English no longer daunting or boring knowledge, but a vivid and witty practice. The original English film can also stimulate interest and enthusiasm on the basis of personal interests, such as the humor of the language and the attraction of the plot. The charm of the film is not only to catch the attention of the audience, but also to bring the audience into the language world of the film, because the lines of the original film are all. It's the most authentic English or American English pronunciation. It has the characteristics of pure pronunciation, fast speech speed and accurate pronunciation.

\section{Cross-Cultural ConteXt AND ENGlish Film ApPreciation}

Cross-cultural awareness refers to the sensitivity cognition of participants to cultural factors in intercultural communication. Haney divides cross-cultural awareness into four levels: at the first level, learners understand the apparent cultural features of the surface through tourism, magazines, textbooks and so on, but he thinks it is peculiar and not understandable. At the second level, some meaningful but subtle cultural characteristics, which are distinct from their own culture, are still not understood through some occasions of cultural conflict. At the third level, we can understand the subtle and meaningful cultural characteristics from the perspective of cognition, and understand it from a cognitive perspective. The fourth level, through a thorough experience of its culture, has learned to look at the problem from the point of view of the local people, to achieve the understanding it feels and feel, that is, the ability of "Empathy" and "cultural integration". Zhu Ning (2009) argues that movie is not only a carrier of culture, but also a product of culture. Whether it's homemade, Hong Kong and Taiwan movies or European and American blockbusters, classic films often give us a deep impression. English original movies not only reflect the characteristics of the times of the movie, but also enrich the cultural essence of a region or a country. Yan Feng (2010) argues that although the emotion of the final audience varies from person to person, it can be said that the essence of movie communication is the realization of a viewing experience and the transmission function. Through the appreciation of English movies, let us have a close contact and understanding of a distant country, let our thoughts out of the distance from the fetters, and gallop in the foreign culture.

However, for English learners, English film appreciation can not only enhance the knowledge of English, but also need to understand the deep intercultural phenomenon through the surface of the language. Take the movie Zootopia as an instance, the movie title is Zootopia, which can be split into two English words, zoo and Utopia. Zoo refers to the zoo, and Utopia is a utopian, ideal country. The whole film reflects the social and political problems of the United States with a child's perspective, with profound ideological significance and high artistic value. Judi's inspiring process in a Zootopia is a typical reflection of the American dream. What is the American dream? People who have seen Forrest Gump know that Gump was not good when he was a child, a leg still had trouble, and some intellectual obstacles, but 
he abandoned, did not give up, was brave to insist, and finally got a very high social reputation, this is the American dream. The United States is an immigrant country and can give you a variety of opportunities. No matter your starting point or birth, as long as you work hard, miracles will happen and good luck will come. The American dream is the mainstream value of the American state and the political correctness of the United States.

Second, the two protagonists in the US are not so easy to realize their dreams, because in the United States, all kinds of discrimination are everywhere. In the Zootopia, the protagonist Judi came to the police station on the first day, and the leopard officer at the door said, "Oh! You are so cute!" But Judi thinks that it is a kind of discrimination, and maybe some people think that Judi is too sensitive, and this is just a miniature of American social racial discrimination. The innuendo is the discrimination against black people in American society, and there is much discrimination on the basis of racial discrimination. For example, the police director of the police station is very discriminatory to the small rabbit, which is a manifestation of the discrimination against the vulnerable groups by the strong group. There are still some special discrimination in Zootopia, such as fox Nick, the other protagonist in the movie. As the fox's reputation in the animal world is not so good, Nick has been laughed at and discriminated against from other animals from childhood, which reflects another kind of discrimination in American Society - stereotypes. One of the most notable figures is the sloth, which is the most classic black humor of the film, ironic of the low efficiency of the US transportation administration.

In addition, in the film Forrest Gump, Gump's mother said "Life was like a box of chocolates and you never know which taste you will get." The phrase "Life is like a box of chocolates" is eulogized everywhere. But why do we use chocolate instead of other things here? This requires us to understand the customs and habits of the United States. There are 12 or 24 pieces of chocolate in the United States. Each has a different package and taste, shape and color. There is no sign on the package. It can only be opened and put in the mouth can we know the taste. So, when watching the English original film, it is more important to understand the cross culture phenomenon under the language surface is understood.

The original film is the disseminator of culture. No matter the narrative of the story, the development of the plot and the change of the relationship, there are many places different with Chinese thinking. However, the cultural differences expressed through language can not only be thoroughly analyzed with language analysis, which requires us to understand some of the characteristics of western culture, especially the Anglo American culture. The difference in the way of thinking, language and culture, through a comprehensive understanding of the western history and culture, and the rise of language to the true sense of communication, make English be a bridge and link in cultural communication.

\section{The Appreciation of English Films in the Cross-Cultural ConteXt}

Gary Weaver (1986) uses iceberg theory to explain the multilevel culture. Like iceberg, culture is composed of "aquatic parts" and "underwater parts". The "water part" is visible, easy to identify and it is a dominant culture, including language, national clothing, architecture, festival customs, and $90 \%$ of the iceberg is under the water, is invisible, that is the recessive culture. Recessive represents the spiritual level, which refers to the cultural differences of the ethnic groups, implied differences in beliefs, values and ideology. For English learners, traditional classroom teaching focuses more on the input of explicit culture, ignoring the interpretation of recessive culture.

\section{A. The Appreciation of Dominant Culture}

Material culture is the most basic communication language in everyday life. More often, it is expressed as a colloquial expression. Only by understanding and mastering these knowledge can we understand the meaning of the film accurately. The appreciation of the dominant culture in English movies can be reflected in the language, dress and architecture of the movie. For English learners, it mainly focuses on the oral expression and some classical dialogue. As long as a little attention is paid to these expressions, diligent in imitation and practice, English learners will make a great progress in the improvement of oral English and the cultivation of cross-cultural awareness.

1. Colloquial expression

Rich spoken English, idioms and slang materials in English movies are the most effective and convenient way to understand the culture of English speaking countries. Many movie dialogues contain a large number of the most vivid words and languages in everyday life in western society. For example, there is a line in the film Forrest Gump: From that day on, we were always together. Jenny and. The peas and carrots here is not difficult to understand directly as "peas and carrots", such a hard translation can only make the audience know nothing, and the cause of this phenomenon is the improper understanding of cultural differences. Because in England and America, peas and carrots are often used for cooking together, so they are very closely related. In addition, the dinner scenes often appear in the movie English, in general, will implement the AA, Go Dutch. If you want to pay for yourself, if you ask the other party, according to Chinese thinking habits, we will often think of Let me pay it for you. But it does not conform to the English habit, which is often used in movies: I am buying; This is on me; This is all my bill.

2. Classical lines

While appreciating English movies, we should also analyze and interpret the cross-cultural context behind classical lines. Britain and America have always advocated that life is equal. Freedom is inherent and sacred and inviolable. There are many classic lines in Forrest Gump, which are widely praised by Gump. Zhu Ning (2009) argues that Gump's 
spirit infects many Americans, and it also makes people realize that as long as they stick to their ideals, wishes will always come true. Gump was inborn with a low IQ, and when he was small, his legs were inconvenient, and his feet were with a few kilograms of weight. But the mother did not abandon it, but encouraged his son to be positive and strong, and told him that "life is the same". In fact, the whole movie is filled with "fool Stupid is as stupid does" and "life is like a box of chocolates, the results are often unexpected" (Life was like a box of chocolates). It also indicates the truth that miracles happen every day if we work hard. The movie is regarded as the representative of the American dream, the American spirit by the American audience.

\section{B. The Appreciation of the Recessive Culture}

In English films, in addition to the dominant cultural elements, more hidden culture is hidden behind the dominant culture. It is often not seen directly and realized. English films show the cultural characteristics of a country or region through the plot and dialogue of the film, but for English learners, it is also necessary for English learners to understand the deeper hidden culture through these explicit cultures and thus become a successful intercultural English learner. The implicit cultural factor in the original English film is the cultural factor of the spiritual level, that is, the deep cultural factor. It is the core part of the culture, mainly including the outlook on life, the values, the way of thinking, the national character and so on. The concept of value is the core of a society's culture. Because of the difference of political system, there are great differences between eastern and Western values. In the western concept, they advocate individualism and equal rights. Next, from the three aspects of westerners' religion, death and individualism, this paper gives some examples of the spiritual and cultural aspects involved in the movie.

1.The question of religion

The question of religion is an indispensable link in English films. Many religious beliefs are reflected in western movies such as The Da Vinci Code and Se7en and Ten Commandments, and most of the Christian faith, the Bible and the ancient Greek mythology of Rome, is the main source of English, so Western English movie always relates to religion. Without understanding the content of some Western religions, the understanding of the original English film is bound to cause obstacles.

2. Attitudes towards death

The eastern and western cultures have different views on the issue of "death". The westerners regard death as part of life, and take a more peaceful attitude towards death. It can be seen from the same scene that westerners choose "churches" for both weddings and funerals. However, in China, the topic of death is evasive and taboo.

In the film Forrest Gump, Gump's mother told Gump before his death: Death is just a part of life. It's something we're all destined to. (Death is just a part of life, is the final destination.)

3. Individualism reflected in the film

Americans advocated "individualism" and "freedom" and "struggle", which was widely accepted. As the film The Shawshank Redemption is the perfect embodiment of the values of American freedom. Andy, a spokesman for "Hope", has been sticking to his original belief in prison for 20 years. He spent 20 years in the prison wall to dig out a way to light and freedom, and realized his pursuit and yearning for freedom. What brings him infinite patience and strength? It is faith and hope, and most of all is the hero's yearning for freedom behind all these surfaces. All these are the strong longing for freedom in the American bones.

\section{English Movie Appreciation Methods}

The first one, introducing cultural background knowledge to reduce the cognitive impairment resulting from it; for non English majors, cultural background knowledge is a barrier to their better understanding of the content of the language and film. Therefore, at first we should understand the cultural background knowledge involved in the movie. In this way, students can form some conceptual categories before appreciating the film, construct certain background schemas and cultural patterns to help understand and memorize the new information in the viewing.

The second, the combination of purposeful learning and unconscious memory; when you watch a movie, there should be a selective arrangement of learning tasks to comprehend the usage and meaning of the English language in different situations and situations.

The third method is to select the suitable film; first of all, the original film itself has its advantages and limitations, its limitations are that any original film is not used to teach language as its language is very random. And all kinds of speech are adulterate. If we don't analyze it, we will be confused. And for a movie, its scenes and characters have certain limitations. This requires that in the course of watching the original English film, we should choose those films with clear pronunciation, moderate degree of difficulty and related to the content of learning.

The last one is the combination of cultural appreciation and skill training. English films are all based on English speaking countries and characters, they are deductive of family, life, social problems and love stories of different times. It has great cultural appreciation. It also provides students with the object of observation and the standard model of imitation. In the process of watching, we will unconsciously compare the language knowledge that we have learned with the modes in the movie. The language and customs of the English speaking countries will be compared with their native customs and patterns. Through these observations, imitates and contrasts, we can successfully and maximally approach the original form of the language, and our hearing ability can be improved first. Psychologists believe that all skills that have been formed can contribute to the formation of new skills, which is called "skill migration". Therefore, 
the improvement of listening ability will naturally contribute to the formation of speaking ability. When we enjoy the original English movies, we should imitate and do some exercises according to the contents of the movies, so as to achieve the migration of listening and speaking.

\section{CONCLUSION}

Intercultural communication is based on the communication between groups with different cultural backgrounds. Since the generation of tribal groups and differences in customs, lifestyles and beliefs, culture begins to spread across tribes and forms an early intercultural communication phenomenon in human society. The appreciation of the original English film is a kind of intercultural communication, but the inherent difference between the East and the West leads to the unequal value between some cultural intentions, which affects the audience's profound understanding of the artistic connotation of the film. There are many ways to appreciate English movies and there are different ways of departure. As an English learner, apart from mastering the knowledge structure of English itself, it is necessary to understand the way of life, customs, ways of thinking, the spirit of humanism and the background of values in the context of the English language, and build a sense of cross culture to better understand the original English version. In the process of appreciation of English films, it is not only to understand the culture of surface meaning and dominance, but to see the essence through the phenomenon and to dig out the profound hidden culture and connotation behind the language. At the same time, we should be perceptible to see the new trend of cultural fusion and cultural symbiosis in the communication of western culture represented by English films. It also requires us to be truly based on the thinking mode of our own nation and to integrate the creativity of western culture and Chinese culture after understanding the cultural essence of the concentrated English film.

\section{REFERENCES}

[1] https://lunwen.7139.com/420/30/169411.html(accessed 20/3/2018).

[2] https://wenku.baidu.com/view/75b1a9e876a20029bd642d6f.html(accessed 18/2/2018).

[3] http://www.jinyueya.com/magazine/26967291.html (accessed 25/2/2018).

[4] http://www.xzbu.com/7/view-6108821.htm (accessed 20/4/2018).

[5] https://www.zhihu.com/question/40023941(accessed 11/3/2018).

[6] https://zhidao.baidu.com/question/1772243252023368020.html(accessed 11/4/2018).

[7] Liu Dan. (2009).Reflections on the cross cultural communication of Chinese films. Journal of Shandong Institute of Commerce and Technology, 9, 92-94.

[8] Li Wenjing. (2010).English original film appreciation and cultivation of intercultural communicative competence. Film Education, 24, 154-155.

[9] Yan Feng. (2010). Reflections on the cross cultural communication of Chinese films -- Taking Hollywood movies as a reference. Chongqing: Northwestern University.

[10] Yu Qiao Qing. (2015). Hayao Miyazaki's animated film research from the perspective of intercultural communication. Liaoning: Liaoning University.

[11] Zhu Ning. (2009). English movie appreciation in cross cultural context. Movie Literature, 14, 144-145.

Tianyu Wang was born in Jiangsu province, China in 1995. She is currently a postgraduate in the College of Foreign Languages, University of Shanghai for Science and Technology, Shanghai, China. Her major is Master of Translation and Interpretation.

Gaofeng Yu was born in Henan province, China in 1959. He is currently an associate professor, M.A., College of Foreign Languages, University of Shanghai for Science and Technology, Shanghai, China. His research interests include translation theory and practice. 